Cite this: RSC Advances, 2013, 3, 18960

\section{New nanocomposite proton conducting membranes based on a core-shell nanofiller for low relative humidity fuel cells $\uparrow$}

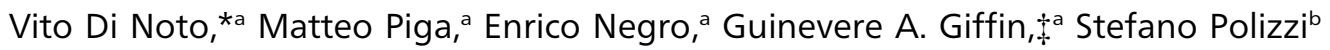 \\ and Thomas A. Zawodzinski ${ }^{\mathrm{C}}$
}

\begin{abstract}
New hybrid inorganic-organic proton conducting membranes containing a ZrTa nanofiller dispersed in a Nafion ${ }^{\circledR}$ matrix are described. The ZrTa nanofiller exhibits a "core-shell" morphology, where the harder $\mathrm{ZrO}_{2}$ forms the "core", which is covered by a "shell" of the softer $\mathrm{Ta}_{2} \mathrm{O}_{5}$. The hybrid membranes are thermally stable up to $170{ }^{\circ} \mathrm{C}$. Interactions between the polymer matrix and the nanofiller increase the thermal stability of both the $-\mathrm{SO}_{3} \mathrm{H}$ groups and the fluorocarbon polymer backbone. In comparison with Nafion, the hybrid membranes have a lower water uptake (W.U.) that depends on the concentration of nanofiller. The residual water, which is approximately 4 wt\%, is likely located at the Nafion-nanofiller interface. Infrared results indicate that the nanofiller does not neutralize all of the $\mathrm{R}-\mathrm{SO}_{3} \mathrm{H}$ groups in the hybrid membrane and the small amount of residual water in the material does not cause the dissociation of the $\mathrm{R}-\mathrm{SO}_{3} \mathrm{H}$ protons. Fuel cell tests show that the maximum power density yielded by the membrane electrode assembly (MEA) containing the hybrid membrane is better than that of the MEA containing Nafion, particularly at low values of relative humidity. The hybrid membranes require much less water to conduct protons effectively and are more efficient at retaining water than Nafion at low water activities.
\end{abstract}

Received 21st January 2013, Accepted 2nd August 2013

DOI: $10.1039 / c 3 r a 40305 j$

www.rsc.org/advances as phosphotungstic acid, allowed the design of PEMFCs with high performances at low relative humidity $(\mathrm{RH})$ and elevated temperature $\left(c a .120{ }^{\circ} \mathrm{C}\right)$. Membranes doped with hygroscopic oxides, such as $\mathrm{SiO}_{2}, \mathrm{TiO}_{2}, \mathrm{ZrO}_{2}, \mathrm{Al}_{2} \mathrm{O}_{3}$ and others, were proposed with the intention of increasing the water uptake of the membranes and decreasing the humidification requirements of the PEMFCs. ${ }^{1-8}\left[\mathrm{Nafion} /\left(\mathrm{SiO}_{2}\right)_{x}\right]$ nanocomposite membranes exhibited the presence of four different water domains. $^{22}$ The silica inorganic filler affects the dynamic relaxations of Nafion and consequently the conductivity of the membrane. ${ }^{22}$ The formation of dynamic $\mathrm{SiO}_{2} \cdots \mathrm{HSO}_{3}-$ crosslinks in the hydrophilic polar clusters, as indicated by the increase in the elastic modulus, influences the chain dynamics of the hydrophobic fluorocarbon domains of the host material. ${ }^{22}$ Other studies were performed on $\left[\mathrm{Nafion} /\left(\mathrm{M}_{x} \mathrm{O}_{y}\right)_{n}\right]$ membranes containing $5 \mathrm{wt} \% \mathrm{Ti}, \mathrm{Zr}, \mathrm{Hf}$, Ta and $\mathrm{W}$ oxides. ${ }^{23,24}$ These studies indicated that: a) the amount of each of the four water domains detected in the bulk membranes depends on the acidity of $\mathrm{M}_{x} \mathrm{O}_{y}$ oxocluster; b) the thermal, mechanical and electrical stability of the Nafion ${ }^{\circledR}$ host polymer depends on the concentration of dynamic $\mathrm{R}-\mathrm{SO}_{3} \mathrm{H} \cdots \mathrm{M}_{x} \mathrm{O}_{y} \cdots \mathrm{HSO}_{3}-\mathrm{R}$ cross-links in bulk material; and c) the concentration and strength of the dynamic $\mathrm{R}-\mathrm{SO}_{3} \mathrm{H} \cdots \mathrm{M}_{x} \mathrm{O}_{y} \cdots \mathrm{HSO}_{3}-\mathrm{R}$ cross-links occurring inside polar hydrophilic cages of the membranes increase along group IV and decrease along period VI of the periodic table. Of these simple metal oxide doped membranes, [Nafion/($\left.\left(\mathrm{HfO}_{2}\right)_{n}\right]$ 
exhibits very favorable physicochemical properties in terms of elastic modulus and conductivity, which result from strong acid-base interactions that occur within the ion aggregate domains between $\mathrm{HfO}_{2}$ and the sulfonic acid groups of host polymer matrix. ${ }^{23,24}$ These interactions are due to the basic nature of $\mathrm{HfO}_{2} \cdot{ }^{23,24}$ It was also shown that the performance of proton-conducting membranes may be improved by blending the proton-conducting ionomer with another polymer bearing basic functionalities. ${ }^{25-27}$

Recently, it was reported that Nafion/[(M1 $\left.\left.\mathrm{O}_{n}\right) \cdot\left(\mathrm{M} 2_{x} \mathrm{O}_{y}\right)_{z}\right]$ membranes show reduced water uptake and improved mechanical properties and proton conductivity as compared to pristine Nafion ${ }^{\mathbb{R}}$ and $\left[\mathrm{Nafion} /\left(\mathrm{M}_{x} \mathrm{O}_{y}\right)_{n}\right]$ membranes. ${ }^{28,29}$ The $\left[\left(\mathrm{M}_{m} \mathrm{O}_{n}\right) \cdot\left(\mathrm{M} 2_{x} \mathrm{O}_{y}\right)_{z}\right]$ nanofiller is prepared by milling together two oxides with different Mohs indices and acidity, which results in a "core-shell" morphology. The nanoparticles consist of a "core" of the harder oxide $\left(\mathrm{M}_{m} \mathrm{O}_{n}\right)$ covered by a thin layer of the softer oxide $\left(\mathrm{M} 2{ }_{x} \mathrm{O}_{y}\right) \cdot{ }^{28,29}$ A study of Nafion/ $\left[\left(\mathrm{ZrO}_{2}\right) \cdot\left(\mathrm{HfO}_{2}\right)_{0.25}\right]$ and $\mathrm{Nafion} /\left[\left(\mathrm{SiO}_{2}\right) \cdot\left(\mathrm{HfO}_{2}\right)_{0.28}\right]$ membranes revealed that the most favorable thermal, mechanical and electrical properties and performance in single fuel cell are obtained for the membranes containing the $\left[\left(\mathrm{ZrO}_{2}\right) \cdot\left(\mathrm{HfO}_{2}\right)_{0.25}\right]$ filler, which has a higher basic character than $\left[\left(\mathrm{SiO}_{2}\right) \cdot\left(\mathrm{HfO}_{2}\right)_{0.28}\right]^{30,31}$ The Nafion/[( $\left.\left(\mathrm{ZrO}_{2}\right) \cdot\left(\mathrm{HfO}_{2}\right)_{0.25}\right]$ materials exhibited a lower water uptake than the Nafion/ $\left[\left(\mathrm{ZrO}_{2}\right) \cdot\left(\mathrm{SiO}_{2}\right)_{0.28}\right]$ membranes and pristine Nafion due to the basicity of the $\left[\left(\mathrm{ZrO}_{2}\right) \cdot\left(\mathrm{HfO}_{2}\right)_{0.25}\right]$ filler. ${ }^{30,31}$

This work aims to elucidate the effect of a nanofiller containing $\mathrm{ZrO}_{2}$ and $\mathrm{Ta}_{2} \mathrm{O}_{5}$ oxoclusters on Nafion's structure and thermal, mechanical and electrical properties. This report describes the synthesis and characterization of the new "coreshell" nanofiller and the preparation of Nafion-based nanocomposite membranes. The new $\mathrm{ZrO}_{2}$ and $\mathrm{Ta}_{2} \mathrm{O}_{5}$-containing nanofiller is prepared with the intent of combining the improvements resulting from fillers with a "core-shell" morphology with the intrinsic characteristics of the individual oxides that will allow it to maintain strong $\mathrm{R}-$ $\mathrm{SO}_{3} \mathrm{H} \cdots\left[\left(\mathrm{M}_{m} \mathrm{O}_{n}\right) \cdot\left(\mathrm{M}_{x} \mathrm{O}_{y}\right)_{z}\right] \cdots \mathrm{HSO}_{3}-\mathrm{R}$ interactions and reduce the water uptake within the hybrid membranes. Of the group IV and period VI oxoclusters previously investigated, ${ }^{22-24,28}$ $\mathrm{ZrO}_{2}$ and $\mathrm{Ta}_{2} \mathrm{O}_{5}$ were selected. The harder $\mathrm{ZrO}_{2}$ has proven to be a suitable "core" to be potentially covered by a $\mathrm{Ta}_{2} \mathrm{O}_{5}$ "shell". ${ }^{30} \mathrm{Ta}_{2} \mathrm{O}_{5}$ has a lower Mohs hardness than $\mathrm{ZrO}_{2}$ and is considerably more expensive, which makes $\mathrm{Ta}_{2} \mathrm{O}_{5}$ a good "shell" candidate. Furthermore, $\mathrm{Ta}_{2} \mathrm{O}_{5}$ is stable in the typical operating conditions of a proton-conducting membrane included in a PEMFC. ${ }^{32}$ The preparation of the nanofiller based on $\mathrm{ZrO}_{2}$ and $\mathrm{Ta}_{2} \mathrm{O}_{5}$, indicated as $\mathrm{ZrTa}$, is part of an effort to produce a "chemical core-shell" nanofiller and subsequently elucidate the effect of its chemistry and surface properties on the structure, properties and fuel cell performance of the resulting hybrid inorganic-organic membranes. ${ }^{30}$ In addition, the water uptake, the thermal and structural properties will be examined. Finally, the performance of the hybrid membrane with $12.8 \mathrm{wt} \%$ of nanofiller will be tested in a single cell configuration at different reagent back pressures and hydration degrees.

\section{Results and discussion}

\section{$\left[\left(\mathrm{ZrO}_{2}\right) \cdot\left(\mathrm{Ta}_{2} \mathrm{O}_{5}\right)_{0.119}\right]$ nanofiller}

Zirconium oxoclusters, when combined with other metal oxides, are particularly good at forming "core-shell" nanofillers. ${ }^{29,30} \mathrm{ZrO}_{2}$ has a high Mohs hardness, which exceeds that of most other oxoclusters. When $\mathrm{ZrO}_{2}$ is milled with other metal oxides, it grinds the softer component into progressively smaller particles. These smaller particles then coat the $\mathrm{ZrO}_{2}$. The coating process of the $\mathrm{ZrO}_{2}$ nanoparticles by $\mathrm{Ta}_{2} \mathrm{O}_{5}$ takes place owing to the formation of metal ion complexes partially coordinated by oxygen atoms on the surface of the hard $\mathrm{ZrO}_{2}{ }^{-}$ based "cores" upon milling. As a result, the surface energy of the $\mathrm{ZrO}_{2}$ nanoparticles is increased, and the surface metal ion complexes are easily coordinated by the surface terminal oxygen atoms of the "soft" $\mathrm{Ta}_{2} \mathrm{O}_{5}$ phase. This solid-state reaction forms strong chemical bonds between $\mathrm{ZrO}_{2}$ "core" nanoparticles and $\mathrm{Ta}_{2} \mathrm{O}_{5}$ "shell" through oxygen bridges. As a result, $\mathrm{ZrO}_{2}$ typically constitutes the "core" of the "core-shell" morphology. In "core-shell" nanofillers previously studied, a $\mathrm{ZrO}_{2}$ "core" was covered by a "shell" of either $\mathrm{SiO}_{2}$ or $\mathrm{HfO}_{2}{ }^{29,30}$ The TEM and ED results are shown for the $\mathrm{ZrTa}$ nanofiller in Fig. 1.

The TEM results illustrate that the milling process significantly reduces the diameter of the particles. The resultant ZrTa nanofiller shown in the low and high magnification TEM images is characterized by smooth, round, polydisperse nanoparticles with diameters between 10 and $50 \mathrm{~nm}$. These images do not indicate the presence of two distinct phases and EDX results (data not shown) did not show evidence of any
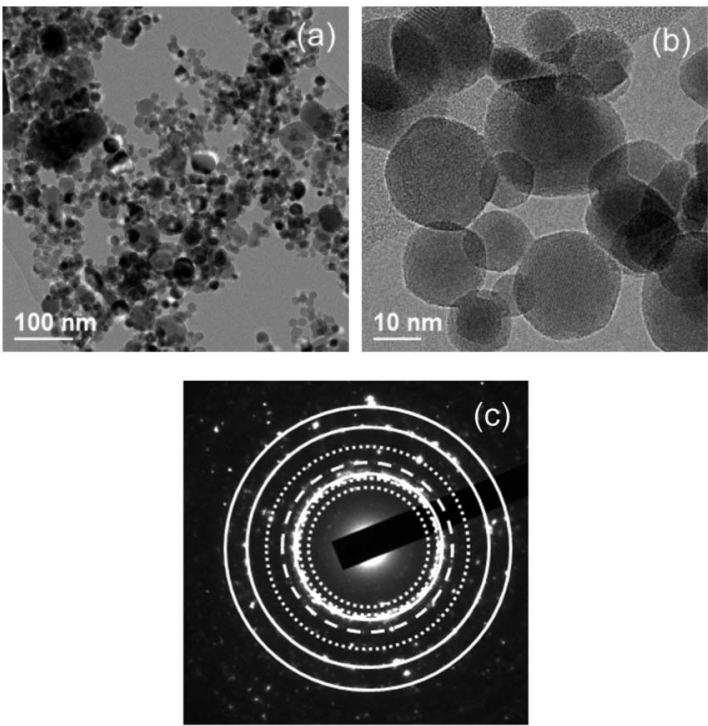

Fig. 1 (a) TEM image $60000 \times$, (b) TEM image $250000 \times$, and (c) ED pattern of the $\mathrm{ZrTa}$ nanofiller. In part $\mathrm{c}$, the circles indicate the following phases: $t-\mathrm{ZrO}_{2}$ (solid line), $m-\mathrm{ZrO}_{2}$ (dashed line) and $m-\mathrm{Ta}_{2} \mathrm{O}_{5}$ (dotted line). 


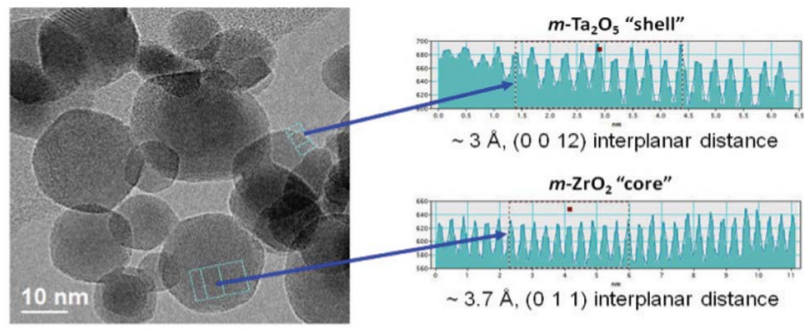

Fig. 2 Spatial distribution of the phases constituting the $\left[\left(\mathrm{ZrO}_{2}\right) \cdot\left(\mathrm{Ta}_{2} \mathrm{O}_{5}\right)_{0.119}\right]$ filler nanoparticles.

grains containing only $\mathrm{Ta}_{2} \mathrm{O}_{5}$. The formation of a "core-shell" structure where $\mathrm{ZrO}_{2}$ is the "core" and $\mathrm{Ta}_{2} \mathrm{O}_{5}$ is the "shell" is supported by analysis of the ED pattern reported in Fig. 1(c). A detailed analysis of the diffraction pattern, which is shown in Table S1 (see ESI $\dagger$ ), revealed the presence of three distinct phases: monoclinic zirconia $\left(m-\mathrm{ZrO}_{2}\right)$, tetragonal zirconia $\left(t-\mathrm{ZrO}_{2}\right)$, and monoclinic $\mathrm{Ta}_{2} \mathrm{O}_{5}$. The spatial distribution of these phases was investigated by examining the EDX spectra of different nanoparticles (see Fig. S1 of ESI $\dagger$ ) in the highresolution TEM image. Both $\mathrm{Zr}$ and Ta were identified in each EDX measurement, which indicates that in the final nanoparticles the $\mathrm{ZrO}_{2}$ and $\mathrm{Ta}_{2} \mathrm{O}_{5}$ components are in close contact. The interplanar distances of the nanoparticle "core" is consistent with $\mathrm{ZrO}_{2}$ phases, while the pattern revealed at the outer edges of the nanoparticles can be attributed to monoclinic $\mathrm{Ta}_{2} \mathrm{O}_{5}$ as shown in Fig. 2 .

$\mathrm{ZrO}_{2}$ and $\mathrm{Ta}_{2} \mathrm{O}_{5}$ are never observed separately in distinct nanoparticles. These results indicate that the ZrTa nanofiller is characterized by a "core-shell" structure, where a "core" of $\mathrm{ZrO}_{2}$ is covered by a thin "shell" of $\mathrm{Ta}_{2} \mathrm{O}_{5}$ and that there is a strong interaction between the two components. Previous studies have classified the "core-shell" nanofillers into two classes, A and B, based on the interactions between the oxides forming the "core" and the "shell" of the nanoparticles. ${ }^{30}$ In A-type "core-shell" nanoparticles, the harder "core" is chemically covered by a "shell" of a softer oxocluster. A chemical-bonding interaction occurs between the "shell" and the "core" oxides when the two components have compatible crystal structures and chemical behavior. In the B-type "coreshell" particles, there is a simple adhesion of the soft component onto the surface of the harder "core". As a consequence, the soft and hard phases are clearly distinguishable. This occurs when the two components have very different and incompatible crystal structures. ${ }^{30,31}$ Therefore, the TEM and ED results indicate that ZrTa is an A-type "core-shell" nanofiller. This morphology has already been observed in other $\mathrm{ZrO}_{2}$-based "core-shell" nanoparticles such as $\left[\left(\mathrm{ZrO}_{2}\right) \cdot\left(\mathrm{HfO}_{2}\right)_{0.25}\right] \cdot{ }^{29,30}$

\section{Water uptake and thermal analysis}

Water uptake by the hybrid membranes was measured by isothermal elimination at 30 and $120{ }^{\circ} \mathrm{C}$ by using the isothermal mass elimination of the materials as shown in eqn (1): ${ }^{23,33}$

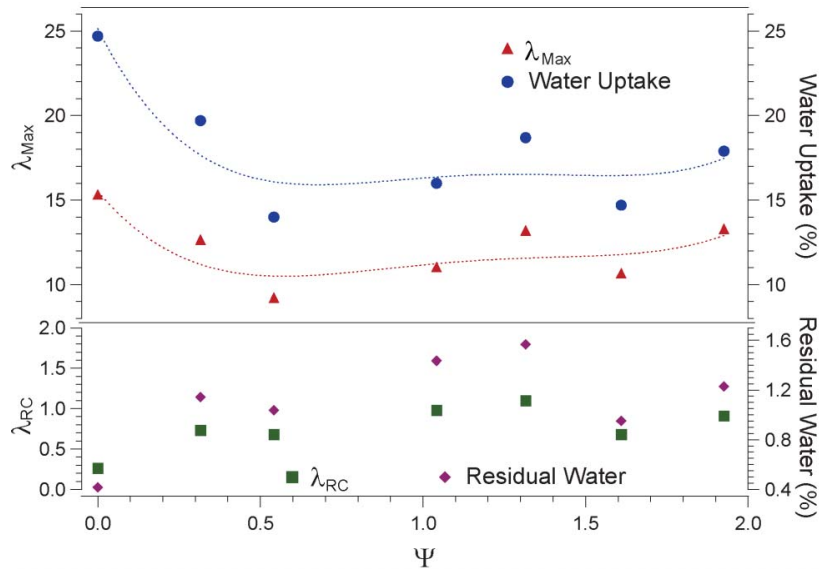

Fig. 3 Dependence of $\lambda_{R C}$ and residual water (bottom) and W.U. and $\lambda_{\max }$ (top) on $\Psi$. $\lambda_{\mathrm{RC}}=\lambda(t=60 \mathrm{~min}, \mathrm{RT})-\lambda\left(T=120^{\circ} \mathrm{C}\right.$ and $\left.t=120 \mathrm{~min}\right)$. The dashed lines are a guide for the eye.

$$
\mathrm{W} . \mathrm{U} .=\frac{\mathrm{wt}(t)-\mathrm{wt}_{\mathrm{dry}}}{\mathrm{wt}_{\mathrm{dry}}}
$$

where $\mathrm{wt}(t)$ and $\mathrm{wt}_{\mathrm{dry}}$ are the weight of the membrane at time $t$ and in dry conditions, respectively. The W.U. has been reported as $\lambda$, which is the number of moles of water per equivalent of acid groups and is determined as in eqn (2):

$$
\lambda(t)=\left[\frac{\mathrm{W} . \mathrm{U} .}{\varphi \cdot \mathrm{MW}_{\mathrm{H}_{2} \mathrm{O}}}\right]
$$

where $\mathrm{MW}_{\mathrm{H}_{2} \mathrm{O}}$ is the molecular weight of water and $\varphi$ is the proton exchange capacity of hybrid membrane. The profiles of $\lambda$ (moles of water per equivalent of acid groups) and W.U. calculated with eqn (1) and (2) are shown in top part of Fig. 3 as a function of the nanofiller concentration $\Psi$.

The term $\lambda_{\max }$ corresponds to the $\lambda$ value determined from the $\mathrm{wt} \%$ of water obtained from the W.U. measurements. The water uptake of pristine Nafion is about $25 \mathrm{wt} \%$, which is consistent with the literature. ${ }^{33,34}$ The W.U. and $\lambda_{\max }$ of hybrid membranes is lower than pristine Nafion and depends on $\Psi$. W.U. and $\lambda_{\max }$ reach a minimum at $\Psi=0.542$ and then very slowly increases with increasing nanofiller concentration. The dependence of W.U. on $\Psi$ suggests that as the concentration of the filler initially increases the density of interactions between the Nafion matrix and the nanofiller increases. These interactions can be considered dynamic nanofiller-Nafion cross-links with the form $\mathrm{R}-\mathrm{SO}_{3} \mathrm{H} \cdots[\mathrm{ZrTa}] \cdots \mathrm{HSO}_{3}-\mathrm{R}$. An increased interaction between the matrix and the filler results in an effect that is similar to chemical cross-linking and improves the membrane ability to resist swelling, which reduces the amount of water absorbed by the membranes. Above $\Psi=0.542$, W.U. and $\lambda_{\text {max }}$ do not change significantly suggesting that further increases in the nanofiller concentration do not continue to improve the membrane resistance to swelling and therefore the W.U. The residual water $\left(\lambda_{\mathrm{RC}}=\lambda(t=\right.$ $60 \mathrm{~min}, \mathrm{RT})-\lambda\left(T=120{ }^{\circ} \mathrm{C}\right.$ and $\left.\left.t=120 \mathrm{~min}\right)\right)$ is reported in bottom part of Fig. $3 . \lambda_{\mathrm{RC}}$ is between 0.2 and 1.1 and slightly 


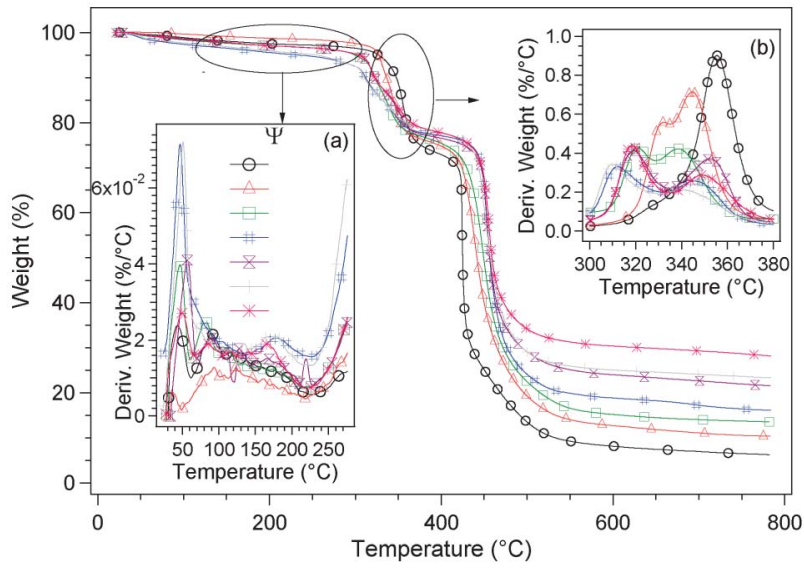

Fig. 4 TG measurements of the $\left[\mathrm{Nafion} /(\mathrm{ZrTa})_{\Psi}\right]$ membranes. The insets show the derivative wt\% TG profiles in the temperature regions: (a) $30-270{ }^{\circ} \mathrm{C}$; and (b) $300-380{ }^{\circ} \mathrm{C}$.

increases with the nanofiller concentration, which is reasonable given the hygroscopic character of ZrTa. This result is important because it indicates that the presence of the inorganic nanofiller increases the adsorption of water molecules, which are likely located at the Nafion-nanofiller interface. The thermal stability of the composite membranes was studied with thermogravimetric analysis.

The TG profiles shown in Fig. 4 reveal that the hybrid membranes are thermally stable up to $c a .160{ }^{\circ} \mathrm{C}$. There are four thermal decompositions. Between 30 and $130{ }^{\circ} \mathrm{C}$, the mass elimination corresponds to traces of water (less than 4 wt $\%$ ). The mass elimination between 130 and $250{ }^{\circ} \mathrm{C}$, which is evident in the derivative of the $\mathrm{wt} \%$ shown in Fig. 4 inset a, is associated with the degradation of $-\mathrm{SO}_{3} \mathrm{H}$ groups and is in agreement with previous studies. ${ }^{28-30,35}$ The filler has a slight stabilizing effect on the $-\mathrm{SO}_{3} \mathrm{H}$ groups in the composite membranes as compared to pristine Nafion. The weight loss observed between 300 and $380{ }^{\circ} \mathrm{C}$ (Fig. 4 inset b) is associated with the thermal degradation of the polyether side chains. ${ }^{23,24,28-30,35}$ In contrast to the filler's stabilizing effect on the $-\mathrm{SO}_{3} \mathrm{H}$ groups, ZrTa tends to decrease the thermal stability of the polyether side groups likely due to the catalytic effect of the transition metal oxides. ${ }^{30}$ The fourth mass

Table 1 Reagent composition and molar ratios for [Nafion/(ZrTa) $)_{\Psi}$ membranes

\begin{tabular}{|c|c|c|c|c|c|c|c|}
\hline \multicolumn{4}{|c|}{ Reagents } & \multicolumn{4}{|c|}{ Molar ratios } \\
\hline $\mathrm{ZrO}_{2} / \mathrm{g}$ & $\mathrm{Ta}_{2} \mathrm{O}_{5} / \mathrm{g}$ & Nafion/g & $\mathrm{wt}^{\mathrm{a}}{ }^{\mathrm{a}}$ & $\Psi_{\mathrm{ZrO}_{2}}^{b}$ & $\Psi_{\mathrm{Ta}_{2} \mathrm{O}_{5}}^{c}$ & $\Psi^{d}$ & $\varphi^{e} /$ meq $^{-1}$ \\
\hline- & - & 0.45 & 0 & 0.000 & 0.000 & 0.000 & 0.9 \\
\hline 0.0141 & 0.0060 & 0.45 & 4.3 & 0.283 & 0.034 & 0.316 & 0.8705 \\
\hline 0.0242 & 0.0103 & 0.45 & 7.1 & 0.485 & 0.058 & 0.542 & 0.85087 \\
\hline 0.0465 & 0.0198 & 0.45 & 12.8 & 0.932 & 0.111 & 1.042 & 0.81139 \\
\hline 0.0587 & 0.0251 & 0.45 & 15.7 & 1.176 & 0.140 & 1.316 & 0.79168 \\
\hline 0.0718 & 0.0307 & 0.45 & 18.6 & 1.439 & 0.172 & 1.610 & 0.77199 \\
\hline 0.0859 & 0.0367 & 0.45 & 21.4 & 1.721 & 0.205 & 1.926 & 0.75226 \\
\hline
\end{tabular}

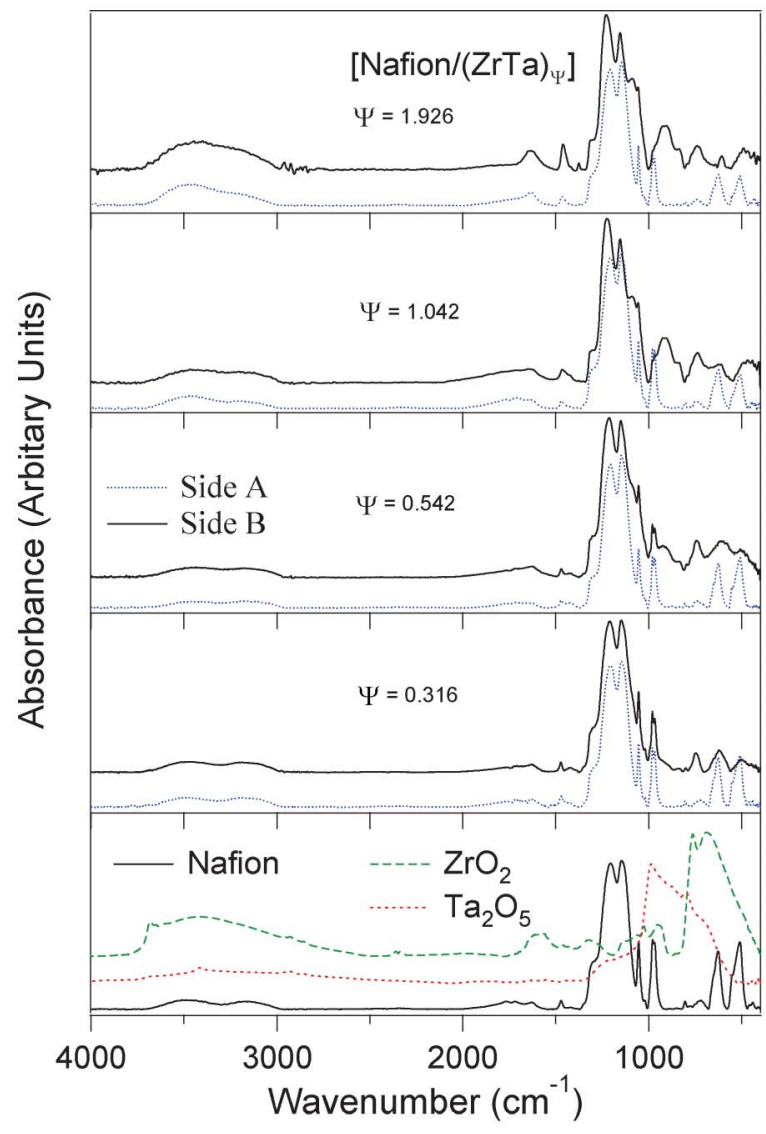

Fig. 5 Vibrational spectra of side A and B of the [Nafion/( $\left.\mathrm{ZrTa})_{\Psi}\right]$ membranes. A is the top surface of the membrane after solvent casting process, while $B$ is the bottom side. The side B spectra are offset vertically for clarity.

elimination, detected between $400-500{ }^{\circ} \mathrm{C}$ range, is due to the decomposition of the fluorocarbon chains of the polymer matrix. $^{22-24,28-30,35}$ The thermal stability of the PTFE chains in the presence of ZrTa is higher than in pristine Nafion. Above $600{ }^{\circ} \mathrm{C}$, the mass residue is related to the amount of the inorganic moiety present in bulk membranes. The trend in the wt\% remaining above $600{ }^{\circ} \mathrm{C}$ is in agreement with the concentration of ZrTa reported in Table 1.

\section{Vibrational spectroscopy}

The compositional asymmetry of the materials is investigated by examining the FT-IR ATR spectra of both sides of the hybrid membrane. Side A is the top of the film after the casting procedure and side $\mathrm{B}$ is the bottom side of the membrane. These spectra are shown in Fig. 5.

At the lowest concentration of $\operatorname{ZrTa}(\Psi=0.316)$ there is little difference in the general peak positions and band intensities. At this concentration, while the filler has a clear effect on the thermal and mechanical properties of the membrane, the concentration of ZrTa is still small enough that its vibrational bands are not visible in the spectrum. However, the interaction of the filler with the Nafion matrix can be detected and is discussed later. As the concentration of the ZrTa nanofiller increases, changes in the vibrational spectra due to the presence of the filler are evident below $c a .1150 \mathrm{~cm}^{-1}$. A 


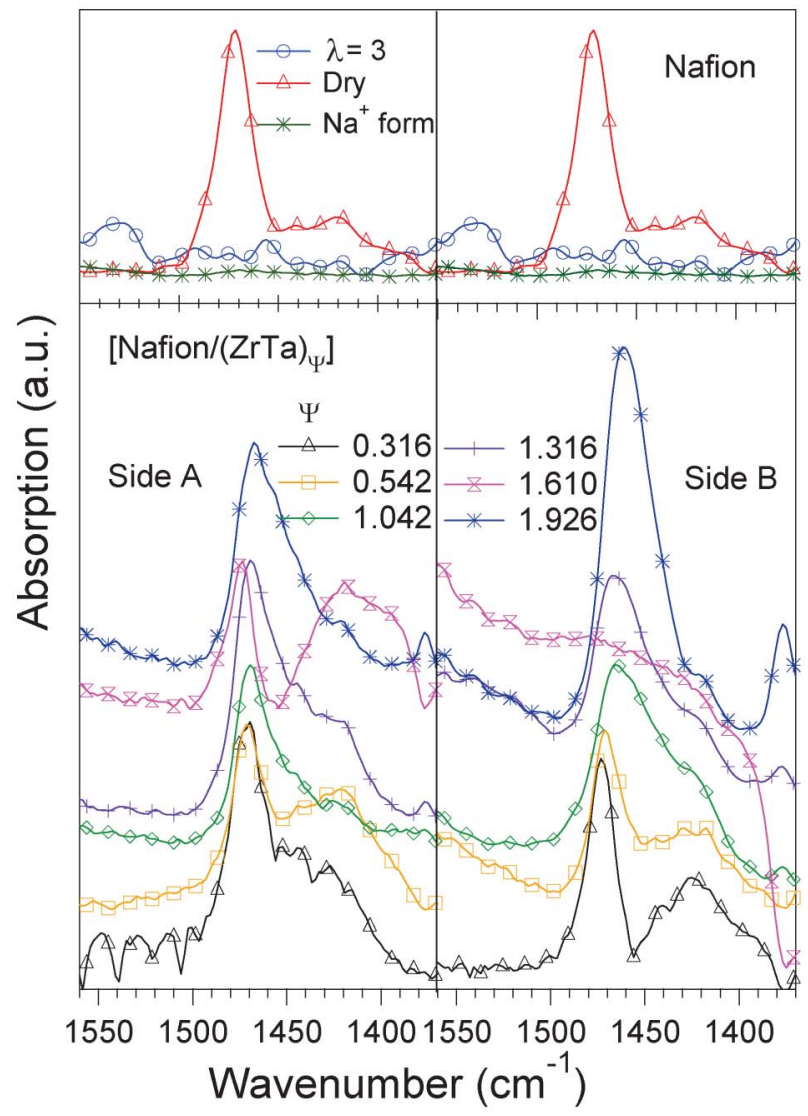

Fig. 6 FT-IR ATR absorption spectra of: (top) dry, $\lambda=3$ and $\mathrm{Na}^{+}$-neutralized Nafion; (bottom) [Nafion/(ZrTa) $)_{\Psi}$ membranes (spectra are offset vertically for clarity).

comparison of the spectra of the $\mathrm{ZrO}_{2}$ and $\mathrm{Ta}_{2} \mathrm{O}_{5}$ oxoclusters and the side $\mathrm{B}$ spectra shows that the presence of new bands in this region is associated with the filler. For $\Psi$ above 1.042, there is little change in the side $\mathrm{B}$ spectra (the two intermediate spectra are not shown). At all concentrations, the side A spectra more closely resemble those of pristine Nafion than the side B spectra, which is not unexpected given that a higher concentration of the filler was clearly visible in the bottom side of the membrane, i.e. the bottom of the membranes appeared to have a matte-like finish while the top of the membranes was glossy. Interactions occurring between Nafion side groups and the ZrTa nanofiller are investigated by comparing the acid spectral region of the nanocomposite membranes with that of dry, $\lambda=3$ and $\mathrm{Na}^{+}$-neutralized Nafion, in Fig. 6.

The peak centered at $1470 \mathrm{~cm}^{-1}$, which is present in dry Nafion but is absent in the $\lambda=3$ (where the proton is dissociated due to the presence of water molecules solvating the sulfonic acid groups) and $\mathrm{Na}^{+}$-neutralized Nafion spectra, is assigned here to the $\mathrm{OH}$ bending mode, $\delta(\mathrm{OH})$, of the $-\mathrm{SO}_{3} \mathrm{H}$ moiety. This peak is typically not reported in the literature and is generally only seen in very dry conditions due to the dissociation of the acidic proton in the presence of even small amounts of water $(\lambda>1)$. The presence of the $\delta(\mathrm{OH})$ band indicates that the nanofiller does not neutralize all of the R-
$\mathrm{SO}_{3} \mathrm{H}$ side groups and any residual water present in the membranes does not cause the dissociation of the sulfonic acid protons. In pristine dry Nafion, this band is reasonably symmetrical and there seems to be low intensity contributions at 1440 and $1420 \mathrm{~cm}^{-1}$. The high frequency contribution $(1470$ $\mathrm{cm}^{-1}$ ) is likely from $\mathrm{R}-\mathrm{SO}_{3} \mathrm{H}$ side groups that are strongly interacting with other $\mathrm{R}-\mathrm{SO}_{3} \mathrm{H}$ side groups or any small amount of residual water $(\lambda<1)$ within the system. As the degree of interaction between the $\mathrm{R}-\mathrm{SO}_{3} \mathrm{H}$ side groups with the environment decreases, the $\mathrm{OH}$ bending mode shifts to lower frequency due to a decrease in the vibrational force constant associated with the bending motion that accounts for the low intensities seen between the band center and $1420 \mathrm{~cm}^{-1}$. Vibrational modes associated with bending motions respond differently than stretching motions to interactions such as hydrogen bonding with adjacent molecules in the environment. It is well known that the stretching mode of $\mathrm{X}-\mathrm{H}_{n}$ groups, where $\mathrm{X}$ is a highly electronegative atom, shifts to lower frequencies when there is an increased interaction with the environment, e.g. an increase in hydrogen bonding through the $\mathrm{H}$ atom. However, it has also been shown that the bending modes of such groups experience a shift to higher frequency in these conditions. ${ }^{36}$ Therefore, it is expected that the $\mathrm{OH}$ bending mode of the sulfonic acid group shifts to higher frequency upon an increase in its interaction with the surrounding environment (other sulfonic acid groups, residual water, fillers, etc.). In the side A spectra of the hybrid membranes (the Nafion-rich side), the band at $1470 \mathrm{~cm}^{-1}$ is not symmetric but has a low frequency tail that slowly decreases in intensity with increasing ZrTa concentration. The spectra of side $\mathrm{B}$ of the hybrid membranes should be more representative of the interaction of the $\mathrm{R}-\mathrm{SO}_{3} \mathrm{H}$ moieties with the filler, particularly at the highest concentrations of filler. At the highest filler concentration the peak frequency is slightly lower $\left(1461 \mathrm{~cm}^{-1}\right)$ than in the pristine Nafion. According to the interpretation of the spectrum of pristine Nafion, it would seem that the shift of the $\mathrm{OH}$ bending peak to lower frequencies in the $\left[\mathrm{Nafion} /(\mathrm{ZrTa})_{\Psi}\right]$ membranes suggests that there is a weaker interaction of the sulfonate group with the environment. However, this interpretation is in disagreement with the increased stability of the sulfonic acid group determined by TG analysis which indicates a stronger interaction with the environment. The TG and IR data together can be explained if the sulfonic acid group acts as a ligand and coordinates with the ZrTa nanofiller via the sulfonic oxygen atoms. This interaction would result in the $\mathrm{RSO}_{3} \mathrm{H} \cdots[\mathrm{ZrTa}]$ cross-links that lead to the improved stability of the sulfonic acid groups. Coordination in such a geometry could result in improved membrane properties such as the mechanical modulus but could also result in a decreased bending vibration frequency as is seen in these membranes. In addition, it is also likely that the filler reduces the probability of solvation of the sulfonic acid $\mathrm{OH}$ moieties by any of the residual water in the membrane, which is probably absorbed elsewhere on the surface of the ZrTa nanofiller. Detection of this type of coordination interaction via the other sulfonic acid modes is very difficult in the $\left[\mathrm{Nafion} /(\mathrm{ZrTa})_{\Psi}\right]$ membranes because these modes are superimposed with those of the PTFE domains of Nafion in the frequency range $1300-1000 \mathrm{~cm}^{-1} \cdot{ }^{37}$ 


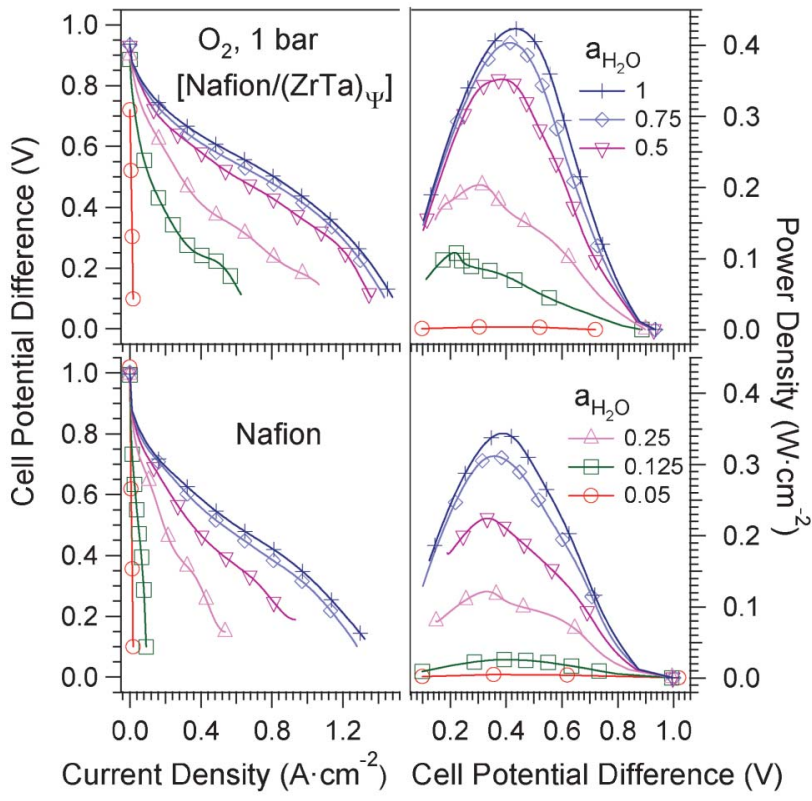

Fig. 7 Polarization and power curves illustrating the single fuel cell performance of the MEAs. The oxidant is pure oxygen, and the back pressure is 1 bar. The membrane thickness is ca. 110 and $140 \mu \mathrm{m}$ for Nafion and [Nafion/(ZrTa) ${ }_{\Psi}$, respectively. The data are not corrected for IR losses.

\section{Fuel cell tests}

The $\left[\mathrm{Nafion} /(\mathrm{ZrTa})_{\Psi}\right]$ membrane with $\Psi=1.042$ was used to fabricate a MEA which was tested in a single-cell configura-

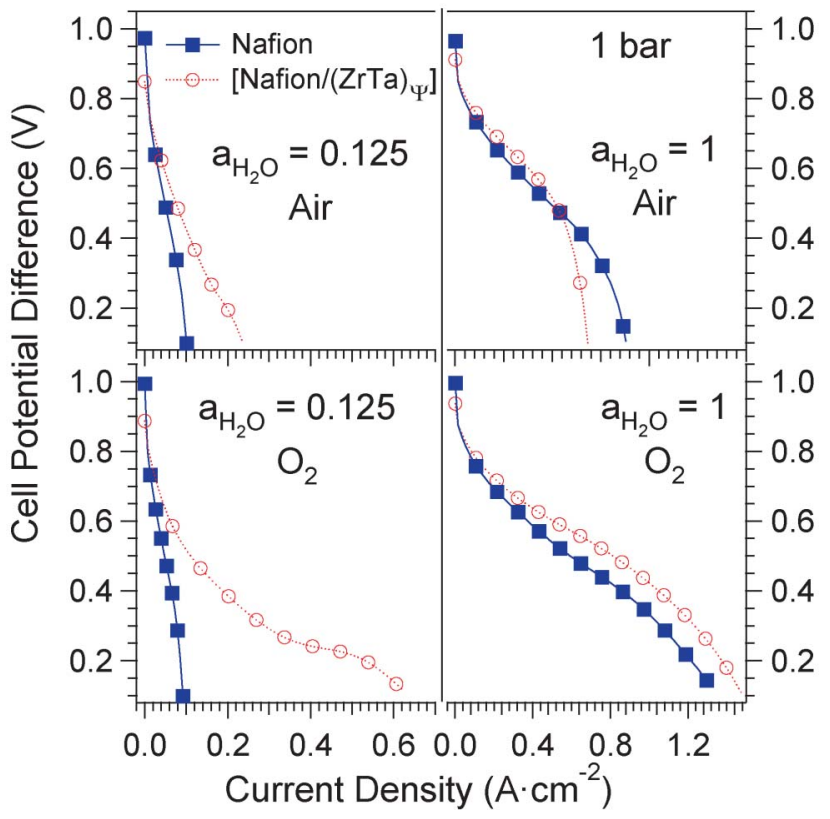

Fig. 8 Polarization curves of Nafion and the $\left[\mathrm{Nafion} /(\mathrm{ZrTa})_{\Psi}\right]$ membrane at low and high degrees of hydration and using either air or pure oxygen as the oxidant. Back pressure of the reagents $=1$ bar. The membrane thickness is ca. 110 and $140 \mu \mathrm{m}$ for Nafion and [Nafion/(ZrTa $)_{\Psi}$ ], respectively. The data are not corrected for IR losses.

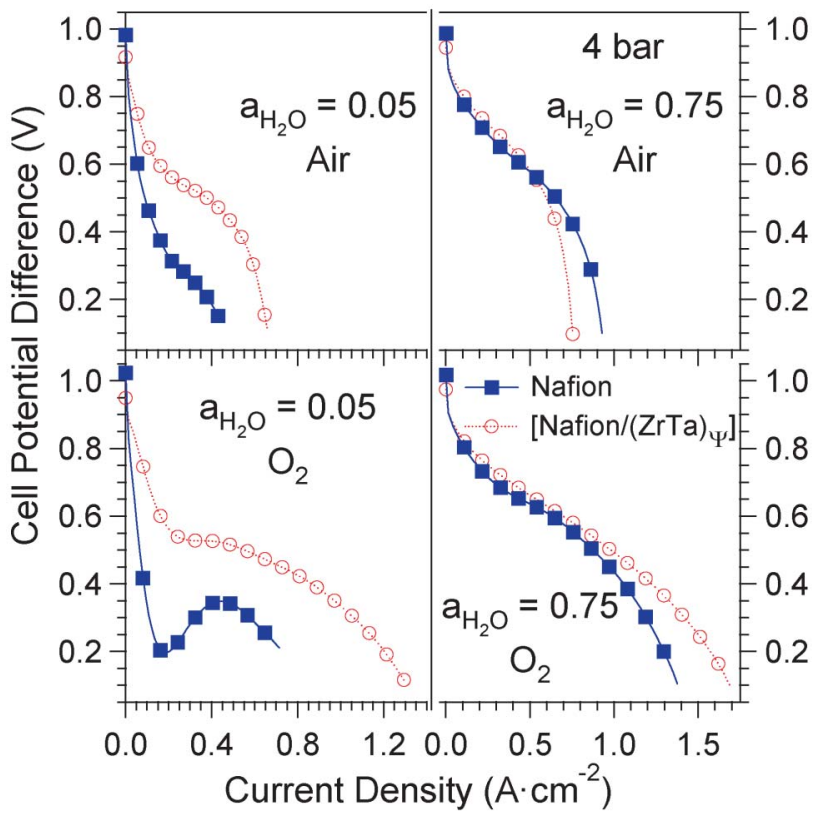

Fig. 9 Polarization curves of Nafion and the [Nafion/( $\left.\mathrm{ZrTa})_{\Psi}\right]$ membrane at low and high degrees of hydration and using either air or pure oxygen as the oxidant. Back pressure of the reagents $=4$ bar. The membrane thickness is ca. 110 and $140 \mu \mathrm{m}$ for Nafion and [Nafion/(ZrTa $)_{\Psi}$ ], respectively. The data are not corrected for IR losses.

tion. Fig. 7 reports the polarization and power curves of the MEAs as a function of the activity of the water vapor $\left(a_{\mathrm{H}_{2} \mathrm{O}}\right)$ in the reagent streams at a back pressure of 1 bar and using pure oxygen as the oxidant.

The overall performance of both MEAs significantly increases with increasing $a_{\mathrm{H}_{2} \mathrm{O}}$. This is consistent with the results previously reported for other hybrid inorganic-organic membranes based on Nafion. ${ }^{30,31}$ Similar trends are observed when the oxidant is air. In general, the polarization curves of the MEA containing the hybrid membrane have a higher cell potential difference at a given current density than the polarization curves of the MEA mounting Nafion (Fig. 8 and Fig. 9).

However, if the oxidant is air and the hydration degree is high $\left(a_{\mathrm{H}_{2} \mathrm{O}} \geqslant 0.75\right)$, the polarization curves of the hybrid membrane are improved over those of Nafion only at current densities lower than $c a .0 .5 \mathrm{~A} \mathrm{~cm}^{-2}$. This evidence suggests that the cathode electrode of the MEA fabricated with the hybrid membrane suffers from more severe limitations due to mass transport, probably due to water flooding of the active sites at current densities larger than $c a .0 .5 \mathrm{~A} \mathrm{~cm}^{-2}$. One way to gauge the performance of different MEAs is to compare the maximum of the power density yielded by the system. This approach is particularly appropriate when the MEAs have the same electrodes, formulation of the electrocatalytic layers, membrane thickness, use the same assembly procedure and differ only in the proton-conducting material. ${ }^{30,31}$ An explanation of the fundamentals that justify the validity of this approach has been reported elsewhere. ${ }^{30}$ The main discriminating factor in the maximum of power density is the proton 


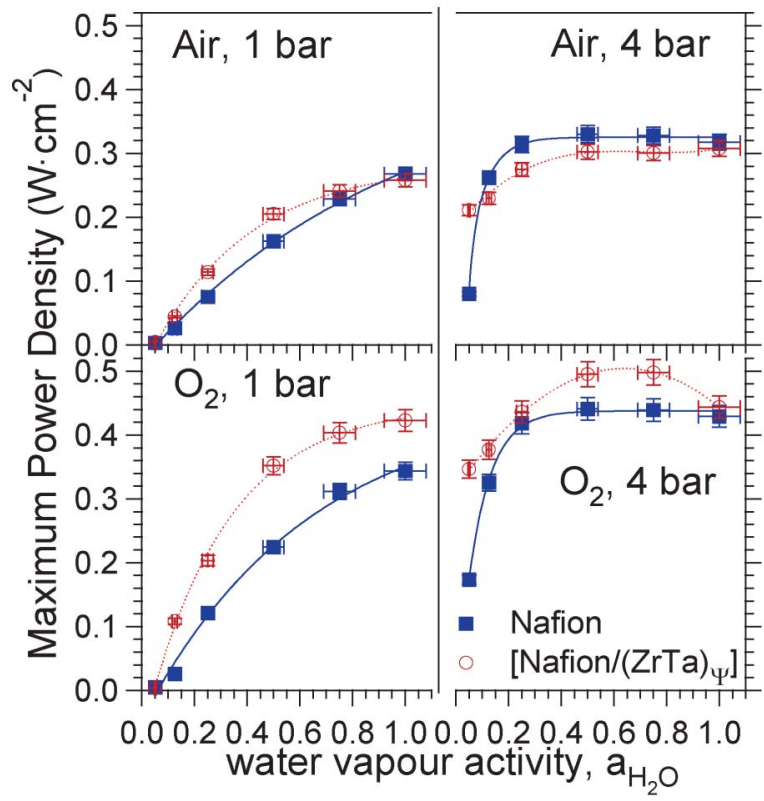

Fig. 10 Dependence of the maxima of power curves on $a_{\mathrm{H}_{2} \mathrm{O}}$ for Nafion and [Nafion/(ZrTa $)_{\Psi}$ ]. The back pressure was either 4 or 1 bar. The oxidant was either air or oxygen. The lines are a guide for the eye. The membrane thickness is ca. 110 and $140 \mu \mathrm{m}$ for Nafion and [Nafion/(ZrTa) $)_{\Psi}$, respectively. The data are not corrected for IR losses.

conductivity of the PEM used in the MEAs. ${ }^{30}$ Fig. 10 shows the maximum power density as a function of $a_{\mathrm{H}_{2} \mathrm{O}}$.

It is observed that the reagent back pressure significantly influences the trends in the maximum power density as a function of $a_{\mathrm{H}_{2} \mathrm{O}}$. At a back pressure of $1 \mathrm{bar}$, the maximum power density curves increase over the whole $a_{\mathrm{H}_{2} \mathrm{O}}$ range, but at a back pressure of 4 bar, a plateau is reached at $a_{\mathrm{H}_{2} \mathrm{O}}>0.25$. These trends are observed for both the hybrid membrane and Nafion. This evidence implies that both PEMs are better able to absorb the available water at the higher back pressure, which improves the proton conductivity and in turn increases the maximum power density values yielded by the MEAs. At a back pressure of $1 \mathrm{bar}$, the membranes are completely filled with water only at high $\mathrm{a}_{\mathrm{H}_{2} \mathrm{O}}$, while at a back pressure of 4 bar the membranes are essentially full of water at $a_{\mathrm{H}_{2} \mathrm{O}}>0.25$. It should be noted that the "available water" includes both the water provided by the reagent streams and the water produced at the cathode of the MEA during fuel cell operation. Fig. 10 also highlights that at a back pressure of 4 bar and at $a_{\mathrm{H}_{2} \mathrm{O}}=$ 0.05 the hybrid membrane is able to yield an appreciable power density, which is markedly higher than that of Nafion. This evidence suggests that the hybrid membrane is better able to absorb water in comparison with Nafion. The water produced during fuel cell operation is enough to give the hybrid membrane a sufficient conductivity to yield a nonnegligible power density. At a back pressure of 1 bar, the maximum power density curves of the hybrid membrane are better than those of Nafion when both air and pure $\mathrm{O}_{2}$ are used as the oxidant. However, the improvement is more pronounced with $\mathrm{O}_{2}$. At a back pressure of 4 bar with $\mathrm{O}_{2}$ as the oxidant, the maximum power density curve of the hybrid membrane is higher than that of Nafion. The reverse is true if air is used as the oxidant when $a_{\mathrm{H}_{2} \mathrm{O}} \geqslant 0.13$. To interpret this evidence, it should be noted that the maximum of the power density curves is typically found at a cell potential difference of ca. 0.2-0.4 V, depending on $a_{\mathrm{H}_{2} \mathrm{O}}$, which corresponds to current densities larger than $0.5 \mathrm{~A} \mathrm{~cm}^{-2}$. In these conditions and using air as the oxidant, the water mass transport issues at the cathode electrode discussed above become important, especially at a back pressure of 4 bar. The result is a drop in the polarization curve of the hybrid membrane below that of Nafion, which leads to lower maximum power density values. As discussed above, the fuel cell performance of the MEA containing the hybrid membrane is improved over that of the MEA with Nafion due to a higher proton conductivity of the [Nafion/(ZrTa $\left.)_{\Psi}\right]$ PEM. This result is consistent with the conductivity data determined on these membranes from "ex situ" techniques reported elsewhere. ${ }^{38}$ At $T=80{ }^{\circ} \mathrm{C}, \mathrm{RH}=100 \%$ the conductivity of $\left[\mathrm{Nafion} /(\mathrm{ZrTa})_{\Psi}\right]$ measured in a sealed cell is equal to $65 \mathrm{mS} \mathrm{cm}^{-1}$; in the same conditions, pristine recast Nafion shows a conductivity of $39 \mathrm{mS} \mathrm{cm}{ }^{-1} \cdot{ }^{38}$ These values are comparable with results found in the literature on similar Nafion-based hybrid inorganic-organic membranes, tested under similar conditions. As an example, Pereira reports that at $T=80{ }^{\circ} \mathrm{C}$ and at $\mathrm{RH}=98 \%$, Nafion $112^{\mathrm{TM}}$ and a hybrid Nafion-silica membrane are characterized by a conductivity of ca. 15 and $25 \mathrm{mS} \mathrm{cm}^{-1}$, respectively. ${ }^{39}$ The hybrid membrane is also better able to absorb the available water, which leads to significantly better performance at low hydration degrees because the membrane maintains sufficient proton conductivity. However, the $\left[\mathrm{Nafion} /(\mathrm{ZrTa})_{\Psi}\right]$ membrane is also less capable of removing excess water, e.g., at high back pressure, high $a_{\mathrm{H}_{2} \mathrm{O}}$ and high current density values where a significant amount of water is produced by fuel cell operation. In these conditions, and when air is the oxidant, the cathode electrode may undergo flooding, thus leading to a decrease in fuel cell performance. When pure $\mathrm{O}_{2}$ is used as the oxidant, the transport of oxygen to the active sites is easier and a decrease in fuel cell performance is not observed. The fuel cell behavior of the $\left[\mathrm{Nafion} /(\mathrm{ZrTa})_{\Psi}\right]$ PEMs may be interpreted by considering that: a) the high water retention ability of the hybrid membrane, as indicated by $\lambda_{\mathrm{RC}}$, results from the water interacting chemically with the nanofiller, e.g. through the solvation of the $\mathrm{R}-\mathrm{SO}_{3} \mathrm{H} \cdots[\mathrm{ZrTa}] \cdots \mathrm{HSO}_{3}-\mathrm{R}$ bridges; and $\mathrm{b}$ ) the "core-shell" ZrTa nanofiller forms percolation pathways in the bulk membrane and acts to reduce the water uptake and consequently the amount of free volume in the hydrophobic domains. These phenomena are responsible for the reduced ability of the hybrid membranes to remove excess water produced at the cathode electrode by back migration to the anodic side during single cell operation with respect to pristine recast Nafion.

\section{Experimental section}

\section{Reagents}

Nafion ${ }^{\circledR}$ with a proton exchange capacity of 0.90 meq $\mathrm{g}^{-1}(5$ wt\% perfluorosulfonic acid PTFE copolymer solution, Alfa 
Aesar, ACS grade) and $\mathrm{M}_{x} \mathrm{O}_{y}$ nanometric oxoclusters (Aldrich, ACS grade), where $\mathrm{M}$ is either $\mathrm{Zr}$ or Ta, were used as received. $\mathrm{ZrO}_{2}$ had an average particle size less than $100 \mathrm{~nm}$, a density of $5.89 \mathrm{~g} \mathrm{~mL}^{-1}$ and is generally characterized by a Mohs hardness of 8.5. $\mathrm{Ta}_{2} \mathrm{O}_{5}$ had an average particle size less than $5 \mu \mathrm{m}$, a density of $8.20 \mathrm{~g} \mathrm{~mL}^{-1}$ and is generally characterized by a Mohs hardness of 7 . Solvents were purchased from Aldrich and used as received. The C2-20 electrocatalyst (BASF) with a platinum content of $20 \mathrm{wt} \%$ was used as received in the preparation of all of the membrane-electrode assemblies (MEA). Double-distilled water was used in all procedures.

\section{Nanofiller preparation}

A $12 \mathrm{~mL}$ dimethylformamide (DMF) suspension containing 1.5 $\mathrm{g}$ of $\mathrm{ZrO}_{2}(70 \mathrm{wt} \%)$ and $0.643 \mathrm{~g}$ of $\mathrm{Ta}_{2} \mathrm{O}_{5}$ (30 wt\%) was milled for $5 \mathrm{~h}$ at $500 \mathrm{rpm}$ in a tungsten carbide grinding jar using a planetary ball mill (RETSCH PM 100). The mixture was transferred into a $100 \mathrm{~mL}$ volumetric flask, diluted with DMF and treated in an ultrasonic bath for $1 \mathrm{~h}$. The resulting suspension (A) contained $\left[\left(\mathrm{ZrO}_{2}\right) \cdot\left(\mathrm{Ta}_{2} \mathrm{O}_{5}\right)_{0.119}\right]$ nanoparticles (ZrTa) where the molar ratio between $\mathrm{Ta}_{2} \mathrm{O}_{5}$ and $\mathrm{ZrO}_{2}$ was 0.119 .

\section{Membrane preparation}

Nanocomposite membranes, where $\Psi=\left(\operatorname{mol}_{\mathrm{ZrO}_{2}}+\operatorname{mol}_{\mathrm{Ta}_{2} \mathrm{O}_{5}}\right) /$ $\mathrm{mol}_{-\mathrm{SO}_{3} \mathrm{H}}$, were prepared using a general solvent casting procedure. Nafion (0.45 g) suspended in a water/alcohol mixture was cast in a beaker and heated at $80{ }^{\circ} \mathrm{C}$ for $40 \mathrm{~min}$ to remove the low-boiling solvents. The resulting brittle film was dissolved in DMF and mixed with an appropriate amount of nanofiller suspension A. ${ }^{28,29}$ The mixture was homogenized in an ultrasonic bath for $2 \mathrm{~h}$ and was then recast on a Petri dish at $100{ }^{\circ} \mathrm{C}$ for $10 \mathrm{~h}$ under a hot air stream. The resulting membranes were dislodged from the Petri dish by a treatment with double-distilled water at $c a .60{ }^{\circ} \mathrm{C}$ for $30 \mathrm{~min}$. The membrane was then dried under air at room temperature for 1 $\mathrm{h}$, placed in oven at $130{ }^{\circ} \mathrm{C}$ for $4 \mathrm{~h}$ and hot-pressed at $100{ }^{\circ} \mathrm{C}$ and 68 bar for $5 \mathrm{~min}$. The thickness of the films was between 200 and $280 \mu \mathrm{m}$. The composition and molar ratios of the $\left[\mathrm{Nafion} /(\mathrm{ZrTa})_{\Psi}\right]$ membranes are summarized in Table 1.

\section{Membrane purification and activation}

The hybrid membranes were purified and activated by a series of treatments at $80{ }^{\circ} \mathrm{C}$ as described elsewhere. ${ }^{22,28}$ Each membrane was soaked in double-distilled water, a $3 \mathrm{wt} \%$ solution of $\mathrm{H}_{2} \mathrm{O}_{2}$, a $1 \mathrm{M} \mathrm{H}_{2} \mathrm{SO}_{4}$ solution, and three times in double-distilled water for $1 \mathrm{~h}$. After this treatment, the films were hydrated in an autoclave at 100\% relative humidity, 135 ${ }^{\circ} \mathrm{C}$ and 3.3 bar. This hydrated state was considered the "reference zero point" (RZP) of the membranes thermal history. The membranes were stored in PET bags filled with double-distilled water at room temperature.

\section{Instruments and methods}

The morphology of the nanofiller was examined by transmission electron microscopy (TEM) and electron diffraction (ED) performed using a Jeol 3010 instrument operated at $300 \mathrm{kV}$ with a high-resolution pole piece $(0.17 \mathrm{~nm}$ point-to-point resolution) and equipped with a Gatan slow-scan 794 CCD camera. Energy-dispersive X-ray spectroscopy (EDX) was carried out using an Oxford Instrument EDS detector (Mod. 6636). The sample powders were suspended in isopropanol and a $5 \mu \mathrm{L}$ drop of this suspension was deposited on a holey carbon film supported on $3 \mathrm{~mm}$ copper grid for TEM investigation. Thermogravimetric analyses were performed with a high resolution TGA 2950 (TA Instruments) thermo-

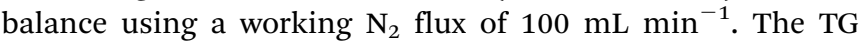
profiles were collected in the temperature range between 20 and $800{ }^{\circ} \mathrm{C}$. Approximately $7 \mathrm{mg}$ of material was analyzed in an open platinum pan. Samples were dried at room temperature for $60 \mathrm{~min}$ prior to measurement. FT-IR ATR spectra were collected at a resolution of $4 \mathrm{~cm}^{-1}$ by averaging 1000 scans with a Nicolet FT-IR Nexus spectrometer equipped with a Perkin-Elmer Frustrated Multiple Internal Reflection accessory 186-0174. The membranes were dried under air for $60 \mathrm{~min}$ prior to measurement collection. The samples for the spectra of dry, $\lambda=3$ and $\mathrm{Na}^{+}$form of Nafion were prepared as follows. ${ }^{28}$ The "dry" sample was dried at $90{ }^{\circ} \mathrm{C}$ under vacuum for $24 \mathrm{~h}$. The " $\lambda=3$ " sample was dried under a dry air flux overnight. The " $\mathrm{Na}^{+}$form" of Nafion was prepared via ion exchange in a $1 \mathrm{M} \mathrm{NaOH}$ solution at $80{ }^{\circ} \mathrm{C}$ and then dried at 90 ${ }^{\circ} \mathrm{C}$ under vacuum for 24 h. W.U. measurements of the nanocomposite films in RZP conditions were conducted in isothermal conditions, heating the samples at $30{ }^{\circ} \mathrm{C}$ for $90 \mathrm{~min}$ and then at $120{ }^{\circ} \mathrm{C}$ for $50 \mathrm{~min}$.

\section{Fabrication of membrane-electrode assemblies}

Pristine recast Nafion and $\left[\mathrm{Nafion} /(\mathrm{ZrTa})_{\Psi}\right]$, where $\Psi=1.042$, membranes were prepared using half of the masses reported in Table 1 and resulted in membranes with a thickness of $c a$. 110 and $140 \mu \mathrm{m}$, respectively. Both membranes were used to fabricate membrane-electrode assemblies (MEAs). The MEAs were prepared with a catalyst-coated substrate procedure as described elsewhere. ${ }^{40}$ The platinum loading in the anodic and the cathodic electrocatalytic layers was $0.4 \mathrm{mg} \mathrm{cm}^{-2}$ and the Nafion-C ratio was 0.3. The electrocatalytic layers were deposited on GDS1120 carbon paper (Ballard Material Products). The resulting gas diffusion electrodes (GDEs) were hot-pressed onto the membranes as previously described. ${ }^{40}$

\section{Tests in a single-cell configuration}

Single fuel cell tests were carried out using a $5 \mathrm{~cm}^{2}$ single cell with a two-channel serpentine flow field for both the anodic and the cathodic sides. Pure hydrogen was used as the fuel and pure oxygen and air were used as the oxidants. The hydrogen flow rate was $800 \mathrm{~mL} \mathrm{~min}^{-1}$. The oxygen and air flow

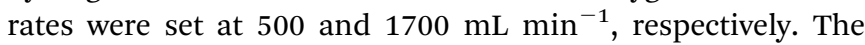
temperature of the cell and reagent streams was maintained at $85{ }^{\circ} \mathrm{C}$. Polarization curves were collected where both reagent streams had water vapour activities of $1,0.75,0.5,0.25,0.125$ and 0.05 at back pressures of 4 and 1 bar on each electrode. The polarization curves were not corrected for internal resistance losses. ${ }^{30,31}$ 


\section{Conclusions}

This report describes the synthesis of hybrid inorganicorganic proton conducting membranes containing the ZrTa nanofiller. The ZrTa filler exhibited a "core-shell" morphology, where the harder $\mathrm{ZrO}_{2}$ forms the "core" and is covered by a "shell" of the softer $\mathrm{Ta}_{2} \mathrm{O}_{5}$. The TEM and ED results indicate that all the sampled particles exhibit a similar morphology and that there are no particles containing only $\mathrm{Ta}_{2} \mathrm{O}_{5}$. It is not possible to distinguish two separated phases, which would indicate that ZrTa is a Type A "core-shell" nanofiller where there is a chemical interaction between the two oxides. The $\mathrm{Ta}_{2} \mathrm{O}_{5}$ content is higher in the "shell", while the "core" is based on $\mathrm{ZrO}_{2}$. The vibrational spectroscopy results indicate that the nanofiller does not neutralize all of the $\mathrm{R}-\mathrm{SO}_{3} \mathrm{H}$ groups in the hybrid membrane and the small amounts of water remaining in the material do not cause the dissociation of all $\mathrm{R}-\mathrm{SO}_{3} \mathrm{H}$ protons. This result suggests that interaction between the ZrTa filler is not a Brønsted-Lowry acid-base type interaction, but may instead form a coordinative interaction where the sulfonate group acts as a ligand. Strong "dynamic" interactions are formed between the sulfonic acid and the filler which results in an increased stability of the acid group, but the shift of the $\delta(\mathrm{OH})$ acid band to lower frequency indicates a decreased interaction between the proton and neighboring groups that implies a decreased vibrational force constant. Taken together, these data support the idea that the interaction between the side group and the filler occurs through the oxygen atoms of the sulfonate groups. The water uptake values of the hybrid materials were lower than that of pristine Nafion and were dependent on the concentration of nanofiller. The residual water content was approximately $4 \%$ and slightly increased with filler concentration. This water can be considered interfacial water located at the interfaces between the Nafion host polymer and ZrTa nanofiller. The hybrid materials are thermally stable up to $170{ }^{\circ} \mathrm{C}$. Interactions between the Nafion host polymer and the nanofiller increase the thermal stability of the $-\mathrm{SO}_{3} \mathrm{H}$ groups and the fluorocarbon backbone, but decrease the stability of the perfluoroether side chains. Single fuel cell tests reveal that the maximum power density of the MEA assembled with the [Nafion/(ZrTa) $\Psi]$ membrane is higher than that of the MEA containing Nafion, particularly at low values of $\mathrm{a}_{\mathrm{H}_{2} \mathrm{O}}$. The improved maximum power density is consistent with higher proton conductivity in the hybrid membrane than in Nafion. The hybrid membranes require less water to conduct protons effectively and are more efficient at retaining water than Nafion at low $a_{\mathrm{H}_{2} \mathrm{O}}$ in the reagents streams.

\section{Acknowledgements}

This research was funded by the Italian PRAT 2011 project, entitled "Advanced nano-electrocatalysts for ethanol oxidation in direct ethanol fuel cells" and Regione del Veneto (SMUPR n. 4148, Polo di ricerca del settore fotovoltaico).

\section{References}

1 G. Alberti and M. Casciola, Annu. Rev. Mater. Res., 2003, 33, 129-154.

2 M. Aparicio and L. C. Klein, J. Electrochem. Soc., 2005, 152, A493-A496.

3 N. H. Jalani, K. Dunn and R. Datta, Electrochim. Acta, 2005, 51, 553-560.

4 K. A. Mauritz, Mater. Sci. Eng., C, 1998, 6, 121-133.

5 M. Nakao and M. Yoshitake, Handbook of Fuel Cells: Fundamentals Technology and Applications, ed., W. Vielstich, A. Lamm, H. A. Gasteiger, 2003, vol. 3, pp. 412419.

6 M. Neergat, K. A. Griedrich and U. Stimming, Handbook of Fuel Cells: Fundamentals Technology and Applications, ed., W. Vielstich, A. Lamm, H. A. Gasteiger, 2003, vol. 4, pp. 856-877.

7 M. B. Satterfield, P. W. Majsztrik, H. Ota, J. B. Benziger and A. B. Bocarsly, J. Polym. Sci., Part B: Polym. Phys., 2006, 44, 2327-2345.

8 T. M. Thampan, N. H. Jalani, P. Choi and R. Datta, J. Electrochem. Soc., 2005, 152, A316-A325.

9 K. T. Adjemian, S. J. Lee, S. Srinivasan, J. Benziger and A. B. Bocarsly, J. Electrochem. Soc., 2002, 149, A256-A261.

10 M. Amjadi, S. Rowshanzamir, S. J. Peighambardoust, M. G. Hosseini and M. H. Eikani, Int. J. Hydrogen Energy, 2010, 35, 9252-9260.

11 M. Casciola, G. Alberti, M. Sganappa and R. Narducci, J. Power Sources, 2006, 162, 141-145.

12 S. Y. Chen, C. C. Han, C. H. Tsai, J. Huang and Y. W. ChenYang, J. Power Sources, 2007, 171, 363-372.

13 M. Helen, B. Viswanathan and S. S. Murthy, J. Membr. Sci., 2007, 292, 98-105.

14 I. Honma, H. Nakajima, O. Nishikawa, T. Sugimoto and S. Nomura, Solid State Ionics, 2003, 162-163, 237-245.

15 R. C. Jiang, H. R. Kunz and J. M. Fenton, J. Membr. Sci., 2006, 272, 116-124.

16 V. Neburchilov, J. Martin, H. Wang and J. Zhang, J. Power Sources, 2007, 169, 221-238.

17 J. Pan, H. Zhang, W. Chen and M. Pan, Int. J. Hydrogen Energy, 2010, 35, 2796-2801.

18 H. S. Thiam, W. R. W. Daud, S. K. Kamarudin, A. B. Mohammad, A. A. H. Kadhum, K. S. Loh and E. H. Majlan, Int. J. Hydrogen Energy, 2011, 36, 3187-3205.

19 D. Truffier-Boutry, G. A. De, L. Guetaz, O. Diat and G. Gebel, Macromolecules, 2007, 40, 8259-8264.

20 K. Wang, S. McDermid, J. Li, N. Kremliakova, P. Kozak, C. Song, Y. Tang, J. Zhang and J. Zhang, J. Power Sources, 2008, 184, 99-103.

21 J. J. Vilatela and D. Eder, ChemSusChem, 2012, 5, 456-478.

22 V. Di Noto, R. Gliubizzi, E. Negro and G. Pace, J. Phys. Chem. B, 2006, 110, 24972-24986.

23 V. Di Noto, R. Gliubizzi, E. Negro, M. Vittadello and G. Pace, Electrochim. Acta, 2007, 53, 1618-1627.

24 V. Di Noto, S. Lavina, E. Negro, M. Vittadello, F. Conti, M. Piga and G. Pace, J. Power Sources, 2009, 187, 57-66.

25 C. M. Ma, Y. Hsiao, Y. Lin, C. Yen, S. Liao, C. Weng, M. Yen, M. Hsiao and F. Weng, J. Power Sources, 2008, 185, 846-852.

26 W. Li, A. Manthiram, M. D. Guiver and B. Liu, Electrochem. Commun., 2010, 12, 607-610. 
27 A. Chromik and J. A. Kerres, Solid State Ionics, 2013, DOI: 10.1016/j.ssi.2013.05.017.

28 V. Di Noto, M. Piga, S. Lavina, E. Negro, K. Yoshida, R. Ito and T. Furukawa, Electrochim. Acta, 2010, 55, 1431-1444.

29 V. Di Noto, M. Piga, L. Piga, S. Polizzi and E. Negro, J. Power Sources, 2008, 178, 561-574.

30 V. Di Noto, N. Boaretto, E. Negro, G. A. Giffin, S. Lavina and S. Polizzi, Int. J. Hydrogen Energy, 2012, 37, 6199-6214.

31 V. Di Noto, N. Boaretto, E. Negro, P. E. Stallworth, S. Lavina, G. A. Giffin and S. G. Greenbaum, Int. J. Hydrogen Energy, 2012, 37, 6215-6227.

32 M. Pourbaix, Atlas of electrochemical equilibria in aqueous solutions, 1st edn, 1966. ch. 9.3, pp. 251-255.

33 T. A. Zawodzinski, C. Derouin, S. Radzinski, R. J. Sherman, V. T. Smith, T. E. Springer and S. Gottesfeld, J. Electrochem. Soc., 1993, 140, 1041-1047.
34 M. Doyle and G. Rajendran, Handbook of Fuel Cells: Fundamentals Technology and Applications, ed., W. Vielstich, A. Lamm, H. A. Gasteiger, 2003, pp. 351-355.

35 M. Vittadello, E. Negro, S. Lavina, G. Pace, A. Safari and V. Di Noto, J. Phys. Chem. B, 2008, 112, 16590-16600.

36 D. Lin-Vien, N. B. Colthup, W. G. Fately and J. G. Grasselli, The Handbook of Infrared and Raman Characteristic Frequencies of Organic Molecules, 1991.

37 M. Danilczuk, L. Lin, S. Schlick, S. J. Hamrock and M. S. Schaberg, J. Power Sources, 2011, 196, 8216-8224.

38 V. Di Noto, M. Piga, G. A. Giffin, K. Vezzù and T. A. Zawodzinski, J. Am. Chem. Soc., 2012, 134, 19099-19107.

39 F. Pereira, K. Vallé, P. Belleville, A. Morin, S. Lamberts and C. Sanchez, Chem. Mater., 2008, 20, 1710-1718.

40 V. Di Noto and E. Negro, Fuel Cells, 2010, 10, 234-244. 